\title{
FINITE ELEMENT ANALYSIS OF CONCRETE SPECIMEN
}

\author{
Farhaan Zaidi Bhat \\ Bachelor Candidate, Department of Civil Engineering \\ SSM College of Engineering, Kashmir, India
}

\begin{abstract}
Finite element analysis is a numerical technique that uses computational power to calculate approximate solution to given problem. Since this method is based on energy principle, it can be used to solve problems related to solid mechanics, fluid mechanics, heat transfer and electrodynamics. This paper compares the experimental results of compression test performed on concrete specimen in laboratory with the numerical results obtained using the finite element analysis of concrete model simulated in ABAQUS software. Compression test of ceramic concrete cubes and cylindrical specimen with M20 concrete characteristics and coarse aggregate partially replaced by Bone-China ceramic was performed in a laboratory. The experimental results obtained were then used as input parameters for the numerical simulations. The strength of the concrete depends on a lot of factors including curing time, temperature, water cement ratio, moisture condition etc., and hence the modelling of the concrete specimen should be done carefully. Concrete damaged plasticity (CDP) model available in software package was used to reflect the behavior of the concrete model in compression as well as tension. Three-dimensional non-linear finite element model was developed and analyzed by the Quasi-static technique using the ABAQUS explicit module. Results show that the model simulated using Finite element method was able to predict the damage behavior of concrete specimen fairly accurately despite the variable nature of concrete. Hence, finite element analysis is an economical and time-efficient method of advanced structural analysis that can be used to study the structural behavior of concrete in compression.
\end{abstract}

Keywords-Finite element analysis; Concrete; Concrete damage plasticity (CDP); ABAQUS

\section{INTRODUCTION}

Concrete is the most widely used construction material in the world and is second only to water as the most utilized substance on the planet. It is obtained by mixing cementing materials, water, aggregates and sometimes admixture. An estimated 33 billion tons of concrete are manufactured globally each year. According to the Press Information Bureau, India generates 62 million tons of waste (mixed waste

\author{
Shaista Kanni \\ Associate Professor, Department of Civil Engineering \\ SSM College of Engineering, Kashmir, India
}

containing both recyclable and non-recyclable waste) every year, with an average annual growth rate of 4\% (PIB 2016). Time to time, different waste materials have been used to replace the constituent material of concrete and determine its effect on the strength of concrete. This paper reports:

(a) the findings on an experimental investigation of the effect of partial replacement of coarse aggregate with Bone-China ceramic waste on strength properties of concrete and

(b) the accuracy of the finite element analysis in comparison to experimental results.

Compressive strength tests were conducted using 150x150x150mm cube specimen and 150x300 mm cylindrical specimen.

In this paper, a 3D nonlinear finite element model is presented to analyze Bone-China ceramic concrete cube subjected to compression load to obtain its ultimate compressive strength. Material damage criteria and analysis technique are very important to be considered in nonlinear finite element analysis in order to obtain a good result up to the ultimate load bearing capacity of the material. Considering the brittle nature of the concrete material, explicit dynamics analysis procedure was employed using ABAQUS/Explicit module. The concrete damaged plasticity (CDP) model as depicted in Figure 1 was used to simulate the Bone China ceramic concrete. It uses stress-strain relationships obtained using experimental methods to correlate parameters for relative concrete damage for both tension and compression. The concrete damaged plasticity model in Abaqus:

- provides a general capability for modelling concrete and other quasi-brittle materials;

- uses concepts of isotropic damaged elasticity in combination with isotropic tensile and compressive plasticity to represent the inelastic behavior of concrete;

- is designed for applications in which concrete is subjected to monotonic, cyclic, and/or dynamic loading under low confining pressures (Abaqus 6.9, 2009). 


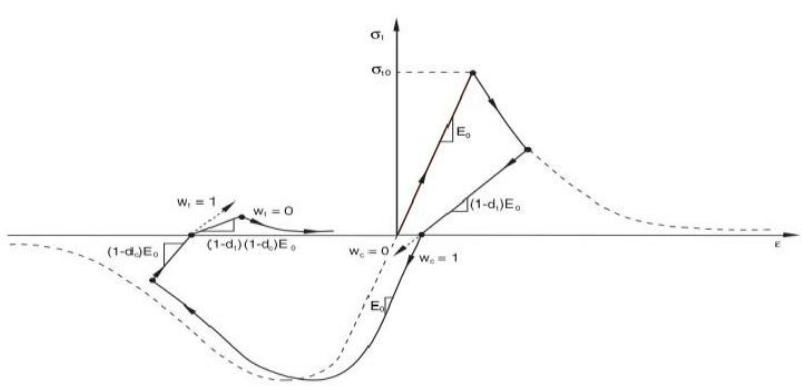

Figure 1. Concrete damaged plasticity modified stress/strain curve

\section{EXPERIMENTAL PROCEDURE}

\section{A. Mix Proportion for producing Bone-China Ceramic concrete}

Materials used in the bone-China ceramic concrete are Coarse aggregate $(20 \mathrm{~mm}-10 \mathrm{~mm})$, Bone China Ceramic waste $(20 \mathrm{~mm}-10 \mathrm{~mm})$, Ordinary Portland cement and fine sand passing through $4.75 \mathrm{~mm}$ sieve. The ratios of the materials are listed in Table 1. 10\% of the coarse aggregate was replaced by bone-China ceramic to determine its effects on the structural strength of concrete having nominal mix ratio of 1:1.5:3 (M20) and a fixed water: cement ratio of 0.45 . The bone-China ceramic concrete was cast into cubes and cylinders. The compression test was conducted over 28 days of casting.

Table 1. Mixture ratio for casting of Bone-China ceramic concrete cube

\begin{tabular}{lcc}
\hline & $\begin{array}{c}\text { Coarse aggregate: Bone } \\
\text { China }\end{array}$ & Water: Cement \\
\hline Ratio & $1: 0.1$ & 0.48 \\
\hline
\end{tabular}

\section{B. Test Configuration \& Instrumentation}

The compressive strength of bone-China ceramic concrete was obtained from the compression test on cubes which was carried out using Universal Testing Machine (Capacity 3000 KN) according to IS 516: Part 5: 1959. The tensile strength of bone-China ceramic concrete was determined from split test on cylinders according to IS 5816:1999 and IS 456:2000. The Young's Modulus value was obtained according to IS 456:2000 as $E_{c}=5000 \sqrt{ } \mathrm{fck}$. Poisson's Ratio was assumed as 0.2 . The difference in the mean compressive strength between the Control sample and the Ceramic specimen was found to vary only about $4 \%$ which is negligible considering the varying nature of the concrete. Hence, it can be concluded that we can use the ceramic waste to replace the coarse aggregate in the concrete satisfactorily up to $10 \%$ without compromising the strength of the concrete.

Table 2. Properties of Bone-China Ceramic concrete

\begin{tabular}{lllllll}
\hline $\begin{array}{l}\text { Dimension } \\
\left(\mathrm{mm}^{3}\right)\end{array}$ & $\begin{array}{l}\text { Pc } \\
(\mathrm{MPa})\end{array}$ & $\begin{array}{l}\text { Fc } \\
(\mathrm{KN})\end{array}$ & $\begin{array}{l}\text { Ft } \\
(\mathrm{KN})\end{array}$ & E (MPa) & Mass & Poisson \\
& & & & $\begin{array}{l}\text { Density } \\
(\mathbf{p})\end{array}$ & Ratio, $\mathbf{v}$ \\
& & & & $(\mathrm{kg} / \mathrm{m} 3)$ & \\
\hline
\end{tabular}

\begin{tabular}{llllllll}
\hline $\mathbf{1 5 0} \times \mathbf{1 5 0}$ & 23.17 & 521.325 & 1.68 & 24067.61 & 2456.47 & 0.2 \\
x 150 & & & & & &
\end{tabular}

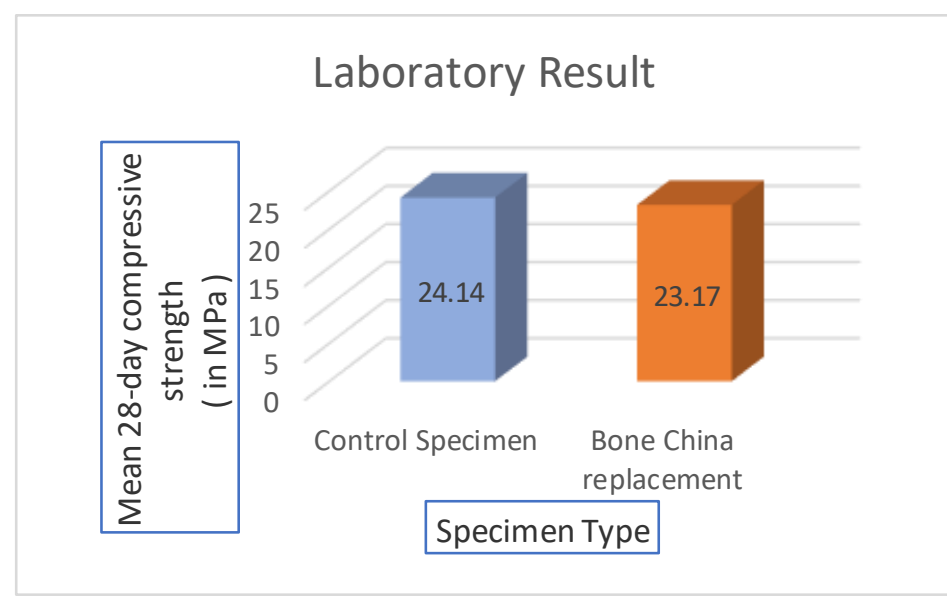

Figure 2. Variation of strength due to coarse aggregate replacement.

\section{FINITE ELEMENT ANALYSIS}

\section{A. Material Properties}

A 3D nonlinear, quasi-static finite element model was developed using ABAQUS/Explicit module to study the behavior of the bone-China concrete cube under compression. Since the variation in result between the M20 concrete and the bone-China replaced concrete was fairly less, material properties required to calculate the concrete damage parameters as input variable to the FE model were obtained from (1) Milad Hafezolghorani, Farzad Hejazi, et al. (Simplified Damage Plasticity Model for Concrete). The damage parameters are calculated based on the stress-strain relations under uniaxial tension and compression loading.

Table 3 shows the constitutive parameters used in simulating the concrete damaged plasticity model in ABAQUS software for both compressive and tensile behavior of M20 concrete material. The parameters listed in Table 3 which were not measurable from the experiment were assumed using values of normal strength concrete (Abaqus 6.9, 2009). Since the concrete damaged plasticity of bone-China ceramic concrete had not been identified by previous research, the concrete damaged plasticity parameters were assumed based on the parameters of normal strength concrete.

Table 3. Concrete damaged plasticity of M20 concrete

\begin{tabular}{|c|c|c|c|c|c|}
\hline \multirow[b]{2}{*}{$\begin{array}{l}\text { Dilation } \\
\text { angle }\end{array}$} & \multirow[b]{2}{*}{ Eccentricity } & \multicolumn{4}{|c|}{$\begin{array}{l}\text { Concrete Damaged } \\
\text { Plasticity }\end{array}$} \\
\hline & & \multicolumn{2}{|c|}{ Uniaxial/Biaxial } & $\mathbf{K}$ & $\begin{array}{l}\text { Viscosity } \\
\text { parameter }\end{array}$ \\
\hline $31^{\circ}$ & 0.1 & 1.16 & & 0.67 & 0 \\
\hline \multicolumn{2}{|c|}{ Compressive } & from & \multicolumn{3}{|c|}{ Tensile Behavior from experiment } \\
\hline
\end{tabular}




\begin{tabular}{|c|c|c|c|c|c|}
\hline \multicolumn{3}{|c|}{ experiment } & \multirow[b]{2}{*}{$\begin{array}{l}\text { Yield } \\
\text { Stress } \\
\text { (MPa) }\end{array}$} & \multirow[b]{2}{*}{$\begin{array}{l}\text { Inelastic } \\
\text { Strain }\end{array}$} & \multirow[b]{2}{*}{$\begin{array}{l}\text { Damage } \\
\text { Parameter } \\
\text { (D) }\end{array}$} \\
\hline $\begin{array}{l}\text { Yield } \\
\text { Stress } \\
\text { (MPa) }\end{array}$ & $\begin{array}{l}\text { Inelastic } \\
\text { Strain }\end{array}$ & $\begin{array}{l}\text { Damage } \\
\text { Parameter } \\
\text { (D) }\end{array}$ & & & \\
\hline 10.2 & 0 & 0 & 2 & 0 & 0 \\
\hline 12.8 & 7.74E-05 & 0 & 0.02 & 0.000943 & 0.99 \\
\hline 15.0 & 0.0001736 & 0 & - & - & - \\
\hline 16.8 & 0.0002887 & 0 & - & - & - \\
\hline 18.2 & 0.0004226 & 0 & - & - & - \\
\hline 19.2 & 0.0005755 & 0 & - & - & - \\
\hline 19.8 & 0.0007472 & 0 & - & - & - \\
\hline 20.0 & 0.0009377 & 0 & - & - & - \\
\hline 19.8 & 0.0011472 & 0.01 & - & - & - \\
\hline 19.2 & 0.0013755 & 0.04 & - & - & - \\
\hline 18.2 & 0.0016226 & 0.09 & & & \\
\hline 16.8 & 0.0018887 & 0.16 & & & \\
\hline 15.0 & 0.0021736 & 0.25 & & & \\
\hline 12.8 & 0.0024774 & 0.36 & & & \\
\hline 10.2 & 0.0028000 & 0.49 & & & \\
\hline 7.20 & 0.0031415 & 0.64 & & & \\
\hline 3.80 & 0.0035019 & 0.81 & & & \\
\hline
\end{tabular}

comparison of compressive strength with experimental results, mesh density with 10164 elements provided a reasonable result as the experiment with reasonable computing time.

Table 4. Result of mesh refinement study

\begin{tabular}{|c|c|c|c|c|c|}
\hline ABAQUS & Total & Total & Fc $(\mathbf{k N})$ & & from \\
\hline $\begin{array}{l}\text { Mesh Type- } \\
\text { Size }\end{array}$ & Nodes & Elements & & Experiment & \\
\hline $\begin{array}{l}\text { Experimental } \\
\text { Data }\end{array}$ & - & - & 521.32 & - & \\
\hline C3D8R - 50 & 100 & 48 & 681.133 & 23.46 & \\
\hline C3D8R -40 & 125 & 64 & 653.64 & 20.24 & \\
\hline$-C 3 D 8 R-25$ & 343 & 216 & 633.043 & 17.64 & \\
\hline C3D8R - 18 & 729 & 512 & 617.965 & 15.63 & \\
\hline C3D8R - 15 & 1331 & 1000 & 610.213 & 14.56 & \\
\hline C3D8R - 12 & 2366 & 1872 & 603.375 & 13.59 & \\
\hline C3D8R - 11 & 3375 & 2744 & 597.843 & 12.79 & \\
\hline C3D8R - 10 & 4624 & 3840 & 596.0 .13 & 12.53 & \\
\hline C3D8R - 9 & 5202 & 4352 & 595.23 & 12.41 & \\
\hline C3D8R -8 & 7220 & 6156 & 592.217 & 11.97 & \\
\hline C3D8R - 7 & 11638 & 10164 & 586.57 & 10.78 & \\
\hline
\end{tabular}

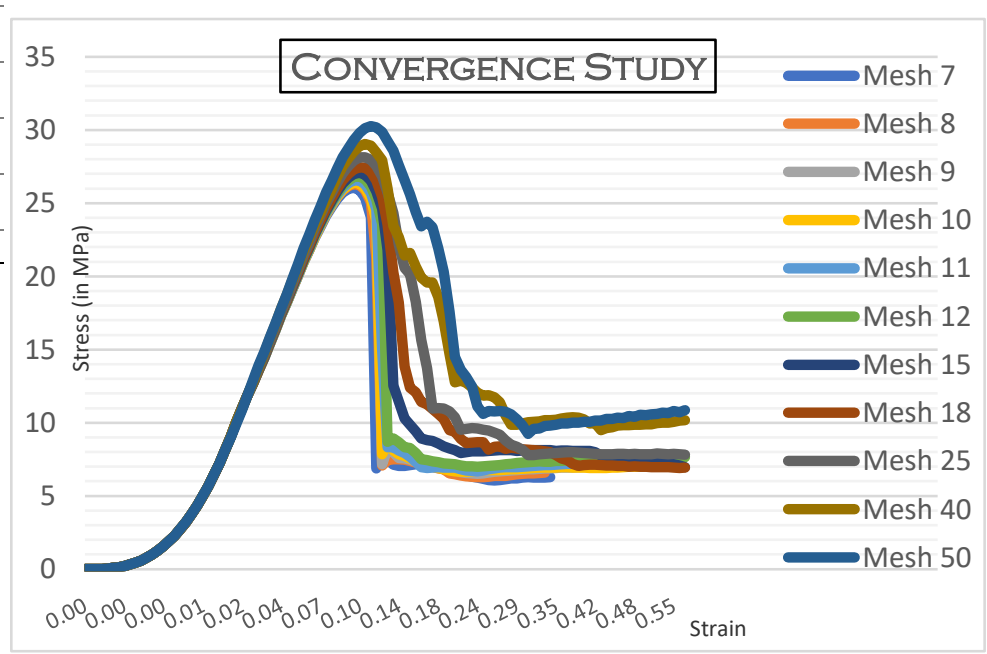

Figure 3. Mesh density study of finite element analysis

\section{B. Failure Behaviour and Crack Pattern}

The stress-strain curves from FE analysis (10164 elements model) were plotted in Figure 4. It can be seen that result achieved ultimate compressive stress with $90 \%$ accuracy as compared to the experimental result with former having a mean value of $23.17 \mathrm{~N} / \mathrm{mm}^{2}$ and latter having value just over $25 \mathrm{~N} / \mathrm{mm}^{2}$.

\section{RESULTS AND DISCUSSION}

\section{A. Effectiveness of Mesh Density}

Models with different mesh refinement were analyzed to determine the best mesh density that gives reasonable accuracy of results and reasonable analysis time. Results of compressive force, $F_{c}$ for various refined element meshes are shown in Table 4 and plotted in Figure 3. From the 
International Journal of Engineering Applied Sciences and Technology, 2021

Vol. 6, Issue 1, ISSN No. 2455-2143, Pages 223-227

Published Online May 2021 in IJEAST (http://www.ijeast.com)
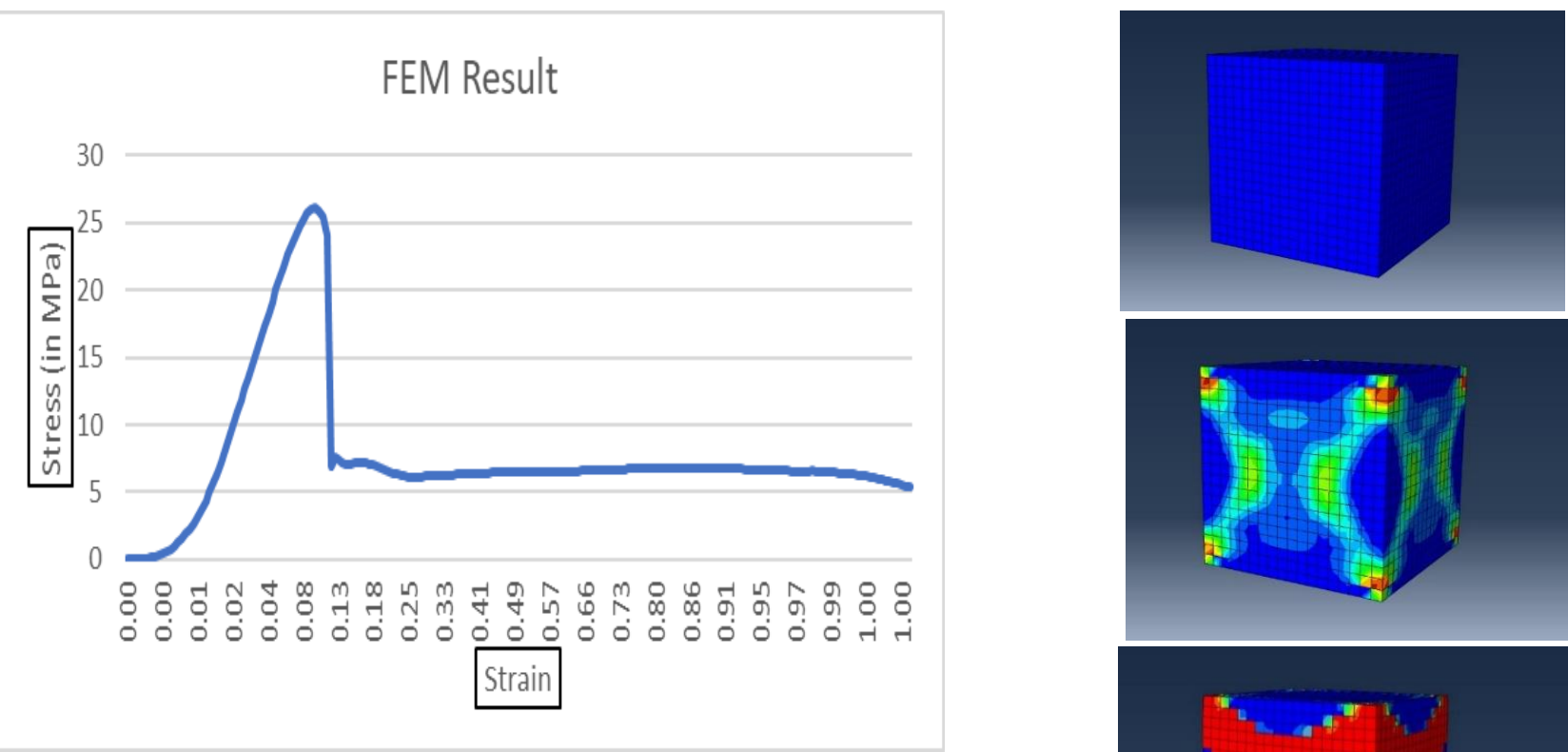

Stage(a)

Figure 4. Finite element analysis result

Failure modes were compared as shown in Figure 5(a) and 5(b). It can be seen that the crack in the experiment had occurred at one corner and along the height of the cube which is identical to the contour plot of the analysis. In the experiment, imperfection of the test specimen, such as uneven cube surface and uneven distribution of bone-china ceramic might had caused the crack to occur only at one corner of the cube.

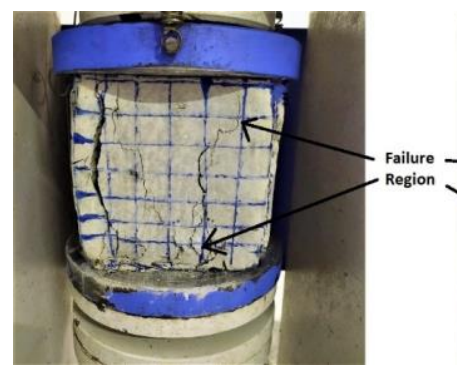

(a) Experimental result

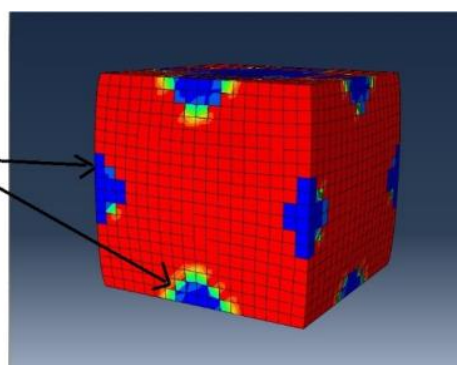

(b) Numerical result

Figure 5. Comparison of failure mode for bone-China ceramic concrete cube

Crack propagations in the concrete cube model are shown in Figure 6 (a), (b), (c), and (d). In Figure 6 (a), the uncracked section is shown. Then, as shown in Figure 6 (b) crack appears near the edge and along the height of concrete and propagate towards the center of the cube and then Figure 6(c) to (d), the concrete cube expended at the middle height due to the compression force applied to it. The maximum load was achieved on stage (b) when the damage occurred. Figure 6 (c) to Figure $6(\mathrm{~d})$ are the condition beyond the maximum load.

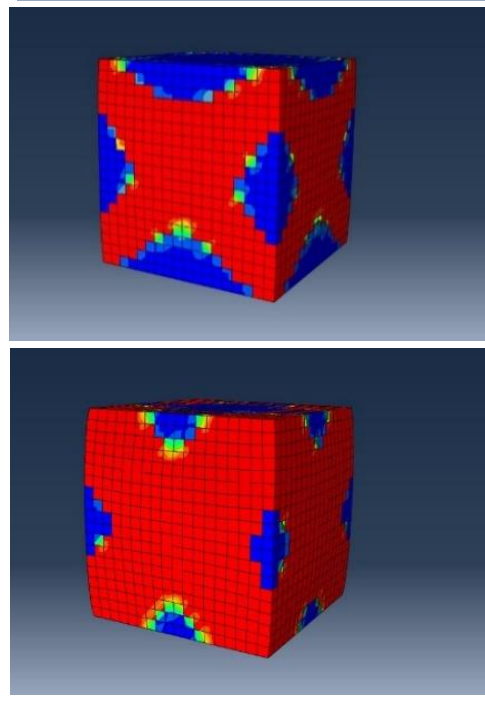

Stage(b)

Stage (c)

Stage(d)

Figure 6. Damage wave propagation of cube from failure, (b) to post failure, (c) \& (d)

Once the constitutive parameters used in concrete damaged plasticity model are known, the resulting ultimate stress of concrete specimen of any shape having those characteristics can be simulated using Finite element analysis. Figure (7) shows the FEA analysis of a cylindrical specimen having same failure criteria as obtained from the experimental results.

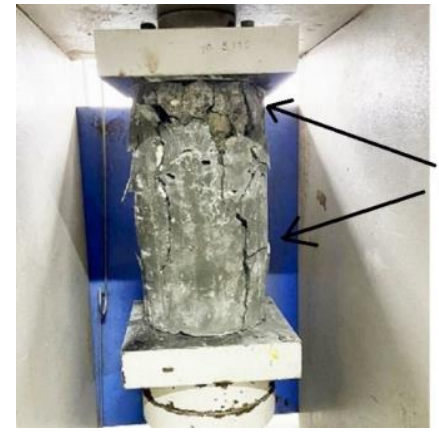

a) Experimental Result

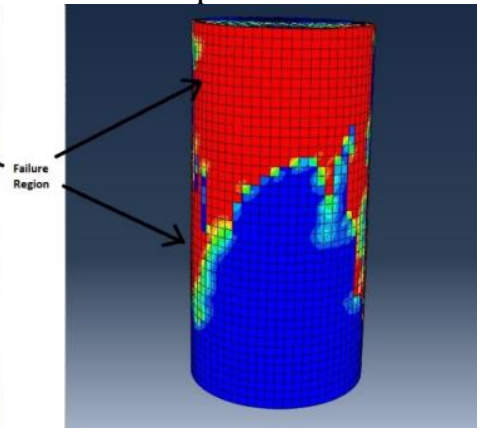

b)Numerical Result 


\section{International Journal of Engineering Applied Sciences and Technology, 2021 Vol. 6, Issue 1, ISSN No. 2455-2143, Pages 223-227 \\ Published Online May 2021 in IJEAST (http://www.ijeast.com)}

Figure 7. Comparison of failure mode for cylindrical specimen

\section{CONCLUSION}

Compression test of the bone-China ceramic concrete cube was modelled and analyzed using finite element method. The concrete was modelled using C3D8R element. The damage criterion for the concrete was modelled with concrete damage plasticity and the material property parameters were obtained from experimental results and partially from (1) Milad Hafezolghorani, Farzad Hejazi, et al. Quasi-static analysis using ABAQUS/ Explicit was employed and the equivalent static result was ensured by controlling the loading period. The result of the study shows that finite element procedure employed in this study can simulate the compression test of the bone China ceramic concrete cube/M20 concrete accurately to a great extent. Increase in the accuracy of concrete parameters results in increased accuracy in finite element results. In spite of the variable nature of concrete and computational limitation, around $90 \%$ accuracy of finite element model in comparison to the experimental results was achieved. Hence, it can be concluded that finite element analysis is a useful computational tool which can be used to solve problems in an economical and time-efficient manner and with the advancement in the field of computer science, this field is bound to reach its full potential. The model and analysis method employed in this study can be used as a guide in modelling the bone-China ceramic concrete/M20 concrete under compression and the accuracy of the model may be increased by variation in the methodology.

\section{ACKNOWLEDGEMENTS}

The author would like to thank SSM College of Engineering and Technology Parihaspora, Pattan, Kashmir especially Shaista Ma'am and Muzammil sir for supporting, guiding me throughout the process. I would also like to thank Chief Engineers office, Rajbagh for providing facilities and services for concrete testing.

\section{REFERENCES}

[1] Milad Hafezolghorani, Farzad Hejazi et al (2017) Simplified Damage Plasticity Model for Concrete DOI: 10.2749/101686616X1081

[2] Wan In Goh, Norida Mohamad, et al (2014) Compression Test and Finite Element Analysis of Foamed Concrete cube Journal of Engineering and Technology Vol 5, No. 1 ,

[3] Jankowial, T., \& Lodygowski T. (2005). Quasi static failure criteria for concrete. Foundations of Civil and Environmental Engineering, 6, 53-69. ISSN 16429303

[4] Simulia D. ABAQUS 6.11 analysis user'smanual. ABAQUS 611 Documentation, 2011

[5] Jason. L, Cabot, P, Huerta G. \& Ghavamian. S. (2004). Damage and plasticity for concrete behavior. European Congress on Computational Methods in Applied Sciences and Engineering, German. pp 1-16.

[6] Lee, J. \& Fenves, G. (1998). Plastic-Damage Model for Cyclic Loading of Concrete Structures. Journal of Engineering Mechanical, 124(8), 892-900.

[7] S. N. Mokhatar \& R. Abdullah. (2012). Computational Analysis of Reinforced Concrete Slabs Subjected to Impact Loads. International Journal of Integrated Engineering, 4(2), 70-76.

[8] Sourav Basak and D.K Paul (2012). Damage Evaluation of a RCC Containment Structure subjected to internal pressure. International Journal of Engineering Science and Technology 4(6), 2823-282

[9] Farhaan Zaidi Bhat (2021) Application of Finite Element Analysis, Researchgate 352017598

[10] Lee J, \& Fenves GL. Plastic-damage modelfor cyclic loading of concrete structures.J. Eng.Mech.1998;124(8): 892-900

[11] Zhang J, Zhang Z, \& Chen C. Yield crite-rion in plasticdamage models for concrete.Acta Mech. Solida Sin.2010;23(3): 220-230

[12] Grassl P, Nystrom U, Rempling R,Gylltoft K. A damage-plasticity model for thedynamic failure of concrete. arXiv preprint2011; arXiv:11031288

[13] Grassl P, Xenos D, Nyström U,Rempling R, \& Gylltoft K. CDPM2: adamage-plasticity approach to modelling thefailure of concrete.Int. J. Solids Struct.2013;50(24): 3805-3816. 